\title{
Error modelling-based machining sequence optimization of a pocketed beam milling: part $A$, end supported beam
}

\author{
Shaoming Yao ${ }^{1}$ \\ Received: 10 September 2020 / Accepted: 15 October 2020 / Published online: 15 February 2021 \\ (C) The Author(s) 2021
}

\begin{abstract}
This paper, on the basis of error modelling, proved the optimal pocket machining sequences of a simply end supported pocketed beam using mathematic induction method. The optimal pocket machining sequence with the minimum pocket floor height error is the machining from both ends to the middle and the optimal sequence is not unique because of the symmetric supports about the central plane; meanwhile, the optimal pocket machining sequence with the minimum wall position error is the machining from the fixed end to the free end and the optimal machining sequence is unique. A beam of A17075 (744 mm in length, $172 \mathrm{~mm}$ in width, and 100 in thickness ) with 9 pockets was used to demonstrate the optimal sequences. One of the optimal sequence with minimum floor height error was used in pocketing (roughing), and the maximum distortion was $0.693 \mathrm{~mm}$ in the middle and the maximum floor height error appeared on both sides rather than the middle, which were $0.477 \mathrm{~mm}$ and $0.388 \mathrm{~mm}$, and part growth produced maximum wall position error was $0.719 \mathrm{~mm}$. On the same part, further demonstrated the optimal sequence with minimum wall position error in finishing (with $1 \mathrm{~mm}$ dimension in stock for all surfaces) and the wall position errors were fully removed. The pocketed beam machining is a typical and representative case and the results and conclusion can be extended to pocketed plate/board machining and even surfacing.
\end{abstract}

Keywords Machining sequence $\cdot$ Pocket machining $\cdot$ Error modelling $\cdot$ Beam milling

\section{Introduction}

In aerospace industry, designs of pocketed beams are popularly used for structure parts, such as ribs and beams to minimize their weight. The distortion produced by material removal and residual stress release tends to make the geometrical error exceeds the assigned tolerance. The pocket machining sequence is one of the issues which affects the geometrical errors produced by distortion.

In 1998, Hornbach and Prevey [1] optimized the machining sequence to minimize the machining distortion of a disc made of nickel alloy. The axial machining distortion of the disc can be reduced from 2.75 to $0.25 \mathrm{~mm}$ with the optimal machining sequence, which was reduced by $91 \%$.

In 2004, Ratchev et al. [2] reported on an integrated method for modelling and prediction of surface error caused by cutting

Shaoming Yao

s.yao@sheffield.ac.uk

1 AMRC with Boeing, The University of Sheffield, Sheffield S60 5TZ, UK force produced deflection during machining of low-rigidity components. The demonstration geometry was a straight wall and the deflection introduced error can be compensated. The quality of the machining outcome relied on the prediction accuracy. It was reasonable to expect that the machining distortion can be compensated or partially compensated if the distortion can be predicted well. However, the machining distortion heavily relies on the machining sequence. Before any active compensation techniques can be applied, the optimal machining sequence with minimized machining error should be sorted out.

In 2005, Wang et al. [3] simulated a pocketed beam by FEM, compared with experiment results, and confirmed the machining distortion of the pocketed beam was because of the residual stress release. The impact of the pocket machining sequence was not considered.

In 2007, Guo et al. [4] developed a FEA-based housebuilding frame modelling method to predict the machining distortion of a large irregularly pocketed board made of aluminum 7075-T7351 and verified with experiment. The pocket machining sequence was neglected and the machining was supposed to happen simultaneously. 
In 2009, Bi et al. [5] developed a method to predict the distortion of a structure part made of aluminum 7050T7451, spar, in machining with 8 pockets. Dimensions were $600 \mathrm{~mm}$ in length, $30 \mathrm{~mm}$ in width, and $11 \mathrm{~mm}$ in height. They used a pocket machining sequence of left to right (one end to another end) and a swirl-out (from inner to outer) tool path for each pocket. The work holding details were not introduced and pocket machining sequence impact was not investigated.

In 2011, Mei et al. [6] analyzed the machining distortion of an arc-shaped work piece (half ring) made of aluminum alloy 2A70 with dimensions amounted to $600 \mathrm{~mm}$ in radius and $60 \mathrm{~mm}$ by $60 \mathrm{~mm}$ in cross section by FEA and experiments. Multiple finger clamps were applied along the part in experiment and fully fixed constrain applied on bottom in FEA model. Twenty-seven machining sequences and methods were compared and the machining distortion in radius varied from -1.3 to $+5.4 \mathrm{~mm}$, which demonstrated the machining sequence impact on the machining distortion is considerable.

In 2016, Cerutti and Mocellin [7] presented the machining sequence impact on a structure part made of AIRWARE®2050-T84, which amounted with 7 transversal pockets/slots. A standard fixture has been used, which used two pins positioning on one side and one pin positioning on the end and two finger clamps hold the part on both ends. They found that machining sequence affected on the distortion by $0.2 \mathrm{~mm}$ and the supposed optimal sequence was used in this work without enough solid evidence. They also co-authored another research paper on machining distortion of a large aluminum aeronautical part with 11 pockets [8]. They compared the clamp number $(2,4$, and 8$)$ effects on machining distortion and proved again the offset changed the bending distortion direction. The pocket machining sequence was not investigated.

In 2017, Jiang et al. [9] reported an approach to predict the distortion of thin-walled parts in milling of an aluminum alloy, A17050, board with 7 pockets. The available machining sequence is the permutation of 7 , which is 5040. They selected 6 out of 5040 to compare the difference and they did find the distortion variation up to $50 \%$. However, it is hard to conclude the optimal one is within the 6 samples. They also compared four tool paths, swirl-out (from inside to outside), swirl-in (from outside to inside), sequential (parallel), and Stype (back and forward), and the deformation varied from 11.3 to $17.4 \mu \mathrm{m}$; clearly, the swirl-in was the best with deformation of $11.3 \mu \mathrm{m}$ but the authors concluded that the swirl-out was the best because of the residual stress. The optimal sequence is still a question as well as the tool path.
Casuso et al. tried to optimize the machining sequence of a hollow vane [10]. He divided the part into six subpasses (removal of the top of the part, four lateral sides, and the central hole) and selected 5 sequences to compare the final maximum displacement and concluded that the machining sequence played a key role in the release of residual stresses and, subsequently, in the final displacement field. However, he cannot conclude the optimal sequence as only 5 out of $6 !(=720)$ sequences compared.

$\mathrm{Li}$ et al. proposed a semi-analytical model for prediction of machining deformation of pocketed boards with regard of machining-induced residual stress and initial residual stress [11]. The machining sequences were ignored and the model is only suitable for deformation prediction of the part profile rather than the machining surface, which heavily relies on machining sequences.

Ye et al. investigated the influence of part position in raw billet on deformation of an aluminum beam with 3 pockets by experiment and finite element method [12]. But the machining sequences were not considered and the results were only for global displacement rather than geometry and dimension errors, which heavily relies on machining sequence. The research only investigated the bending deflection and the part dimension error in length was not studied.

Focusing on the above fundamental issue, the current work is to optimize the pocket machining sequence(s) with the minimized machining distortion produced errors. The error models are created for every cut (pocketing) and the optimal machining sequence with minimum floor height error and that with minimum wall position error are proved by mathematic induction method. The optimal machining sequences are demonstrated the by an aluminum beam with 9 pockets and dimensions of $744 \mathrm{~mm}$ in length, $172 \mathrm{~mm}$ in width, and 100 in thickness.

\section{Idealization, assumptions, and methodology}

The optimization of pocket machining sequence is a general issue in production and a general methodology is required for this challenge.

\subsection{Idealization}

In this case, the pocket size is rather smaller than the part length and it can be idealized as a simply end supported beam with $N$ pocket, as shown in Fig. 1. The machining of the pocket $i$ will produce an initial distortion displacement of $S_{0 i}$ at the center of the pocket $i$, as shown in Fig. 1 . 
Fig. 1 Simply supported beam machining with $N$ pockets and machining of pocket $i$ produced distortion $S_{0 i}$

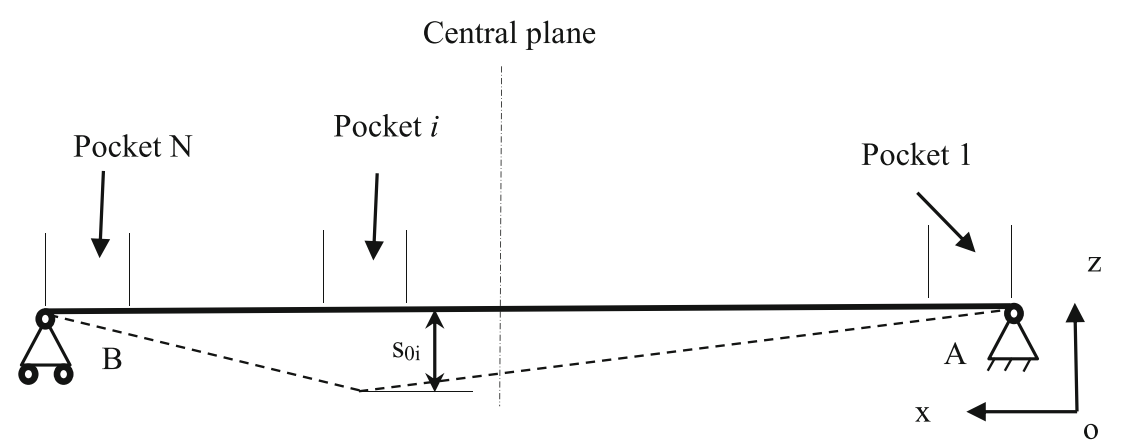

\subsection{Assumptions}

Distortion and error are confusing concepts in machining. To clarify the difference between distortion and error, the distortion is defined as the displacement produced by residual stress release in machining, which distributes within the work piece; the error is defined as the distance between the real surface or point of the work piece and the ideal geometry of the work piece. The distortion only contributes to the error of an existing geometry, such as raw material surface or finished surface, and will not contribute to the error of a non-existing geometry, such as unfinished surface.

Simple supports are applied on both ends of the beam and one end (on the right) is fixed. To simplify the analysis, the following assumptions are made:

(1) Residual stress distribution in the beam cross section is unchanged along the beam.

(2) The pockets are uniform and equally spaced along the beam.

(3) The distortion is negligible compared to the pocket depth.

(4) Back contribution rule: the machining distortion produced by machining of the pocket $i$ only contributes to the machining errors of the previous cuts (pockets) and does not contribute to the machining errors of the after cuts (pockets) and local one (itself), because the distortion can only produce a displacement on an existing geometry (previous cuts produced geometry) and cannot produce a displacement on a non-existing geometry (produced by after/future cuts and current cut).

(5) Part growth far end contribution rule: the machining distortion produced by the machining of the pocket $i$ only contributes to the part growth produced position errors of the pockets far away from the fixed point (right) and does not contribute to the position errors of the pockets that are closer to the fixed point than the current pocket $i$. This assumption applies because the fixed end of the simply support beam cannot move in the whole machining process.

\subsection{Methodology}

On the basis of the above assumptions, the following method is used to find out the optimal pocket machining sequence for a pocketed beam:

(1) Create the error model's every pocket with regard to distortion and contribution of every pocket machining.

(2) Find out the optimal cut 1 with minimum floor height error or minimum wall position error (part growth).

(3) Suppose the optimal cut $i$ (with minimum floor height error or minimum wall position error) is correct.

(4) Prove the optimal cut $i+1$ is correct as well.

After the optimal cut $i+1$ is proven, the optimal machining sequence is obtained.

\section{Optimal sequence with minimum floor height errors}

In the machining of the beam with $N$ pockets and assumptions (1) to (4) apply, as shown in Fig. 5, the optimal cut $i$ with the minimum floor height errors is the machining of pocket $i$ or pocket $N-i+1$, where $N$ is a nature number and $i$ is a natural number from 1 to $N / 2$.

This rule can be proved by mathematic induction (MI) in the following sections.

\subsection{The optimal cut 1}

The optimal cut 1 is the pocket or pockets that can be machined first and the following pocket machining contributes the minimum errors to it or them.

The definition of the initial distortion, $S_{0}$, is composed of $N$ components, $S_{0 i}$, which is produced by pocket $i$ machining only, as shown in Fig. 1:

$$
\left[S_{0}\right]=\left[\begin{array}{llll}
S_{0,1}, & S_{0,2}, \ldots . S_{0, N-1}, & S_{0, N}
\end{array}\right]^{T}
$$


The distortion produced error is $Z$ and

$[Z]=[\xi]\left[S_{0}\right]$

where $[\xi]$ is the contribution matrix,

$$
[\xi]=\left[\begin{array}{ccccc}
\xi(1,1) & & & & \xi(N, 1) \\
& \xi(2,2) & & & \\
& & \ldots & & \\
& & \xi(N-1, N-1) & \xi(N, N)
\end{array}\right]
$$

and

$\xi(i, j)=\left\{\begin{array}{l}\frac{i}{j},(i<j) \\ \frac{N-i+1}{N-j+1},(i>j) \\ 1,(i=j)\end{array}\right.$

where $i=1$ to $N, j=1$ to $N$, and

$$
Z(i)=\sum_{j=1}^{N}\left(\xi(j, i) * S_{0}(j)\right)
$$

If $N=9$, the contribution matrix is

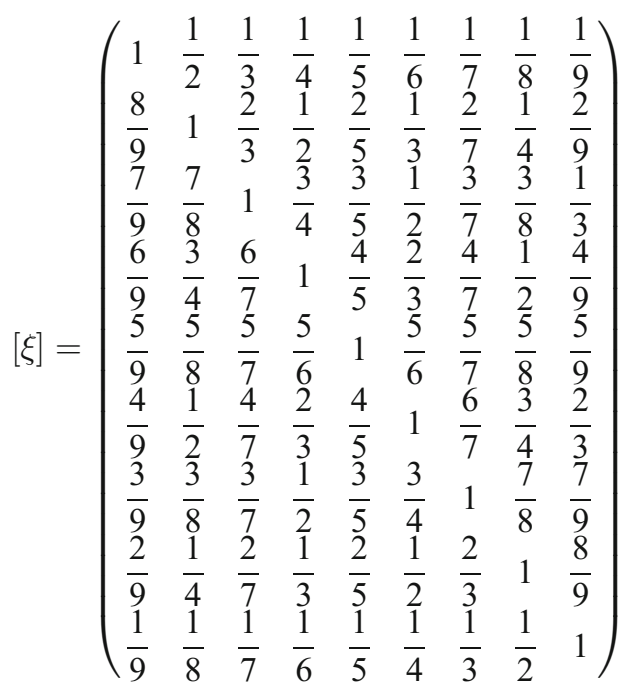

The definition of the distortion produced error is

$$
1\left[E_{\text {bend }}\right]=\left[\begin{array}{ccccc}
e_{b}(1,1) & & & & e_{b}(N, 1) \\
& e_{b}(2,2) & & & \\
& & \cdots & e_{b}(N-1, N-1) & \\
e_{b}(1, N) & & & & e_{b}(N, N)
\end{array}\right]
$$

Because the machining of pocket $i$ will not contribute to the local floor height error, see assumption (4),

$$
e_{b}(i, i)=0
$$

The distortion produced error can be expressed as

$\left[E_{\text {bend }}\right]=[Z]-I\left[S_{0}\right]$

where $I$ is the unit diagonal matrix.

According to the superposition principle, the machining error at pocket $i, \Delta_{i}$, is the sum of the contribution of the pocket from 1 to $N$,

$\Delta_{i}=\sum_{j=1}^{N} e_{b}(i, j)$

The optimal cut 1 should produce the minimum error at the given position,

$\operatorname{Min}(\Delta(i), i \in[1, N])=\operatorname{Min}\left(\sum_{j=1}^{N} e_{b}(i, j), i \in[1, N]\right)$

As the two end supports and pocket distribution are symmetric about the central plane, the optimal cut 1 may be on the left of the central plane or on the right and yields,

$$
\begin{aligned}
& \operatorname{Min}(\Delta(i), i \in[1, N])=\operatorname{Min}\left(\sum_{j=1}^{N} e_{b}(i, j)\right) \\
& =\sum_{j=1}^{N} \operatorname{Min}\left(e_{b}(i, j)\right)=\left\{\begin{array}{c}
i=1, i \in\left[1, \operatorname{int}\left(\frac{N}{2}\right)\right] \\
i=N, i \in\left[\operatorname{int}\left(\frac{N}{2}\right)+1, N\right]
\end{array}\right.
\end{aligned}
$$

Because of the above symmetry, the pocket 1 and pocket $N$ are equivalent. The optimal first cut is composed of two pockets, pocket 1 and $N$. It means either pocket 1 or pocket $N$ can be the first pocket to be machined and the other will be the second. So there are two optional sequences, $(1, N)$ or $(N$, $1)$, for cut 1 .

\subsection{The optimal cut $i$ and $i+1$}

According to mathematical induction method, suppose $k=i$ is correct, that means the optimal cut $i$ is the machining of the pocket $i$ and $N-i+1$, the two pockets are equivalent, and one goes first the other goes the second, which one goes first will not make a big difference.

So the optimal cut $i+1$ is within the pockets from $i+1$ to $N$ $-i$. The machining of pockets $i+1$ to $N-i$ produces a constant displacement, $\Delta_{0 i}$, at the pockets $i$ and $N-i$, which is not affected by the machining sequence of pockets of $i+1$ to $N-i$.

The displacement, $\Delta_{0 i}$, is the sum of the distortions produced by the machining of pockets from $i+1$ to $N-i$ and can be expressed as, 
$\Delta_{0 i}=i \sum_{j=i+1}^{N-i-1} \frac{S_{0 i}}{j}$.

The machining error of every pocket from $i+1$ to $N-i-1$ is composed of an error related to its position and machining sequence of pockets from $i+1$ to $N-i-1$ and a constant displacement, $\Delta_{0 i}$. This is equivalent to the distortion of a beam with simple supports on $\mathrm{C}$ and $\mathrm{D}$, plus as a constant displacement of $\Delta_{0 i}$ as shown in Fig. 2.

For the pockets from $i+1$ to $N-i-1$ with simple supports on $\mathrm{C}$ and $\mathrm{D}$, iterate the above process and the optimal cut $i+1$ is,

$$
\begin{gathered}
\operatorname{Min}(\Delta(k), k \in[i+1, N-i-1])=\sum_{j=i+1}^{N-i-1} \operatorname{Min}\left(e_{b}(k, j)\right) \\
=\left\{\begin{array}{c}
k=i+1, k \in\left[i+1, \operatorname{int}\left(\frac{N}{2}\right)\right] \\
k=N-i-1, k \in\left[\operatorname{int}\left(\frac{N}{2}\right)+1, N-i-1\right]
\end{array}\right.
\end{gathered}
$$

The optimal cut $i+1$ is the machining of pockets $i+1$ and $N-i$, and the two pockets are equivalent and which one goes first will not make a big difference, so the optimal cut $i+1$ can be the machining with sequence of (pocket $i+1, N-i$ ) or (pocket $N-\mathrm{i}, i+1$ ).

According to the above mathematic induction process, it can be concluded the optimal cut $i$ with the minimum floor height error for the simply supported beam with $N$ pockets to be machined is the machining of the pocket $i$ and pocket $N-i$ +1 . In the machining of a simply end supported pocketed beam, the optimal machining sequence with the minimum floor height error on the machining surface is not unique and available equivalent sequences are $2^{\operatorname{int}(N / 2)}$.

\section{Optimal sequence with minimum part growth produced wall position errors}

Residual stress release not only produces distortion and machining error in vertical direction, $y$, but also produces part growth (in length) in horizontal direction, $x$, which results in position errors of the part features, such as the position of walls.

Part growth is the term conventionally used in production environment to describe the dimension change in length or in plane displacement; distortion is most of the time used for the off-plane displacement. Both of them are produced by residual stress release.

\subsection{The optimal cut 1}

The simply supported beam $\mathrm{AB}$ with $N$ pockets is shown in Fig. 3. Point A fixed and machining of the pocket $i$ produced part growth, $L_{0, i}$, as shown Fig. 3 .

The machining of pocket $i$ produces a part growth $L_{0 i}$ and the initial part growth, $L_{0}$, is composed of the component, $L_{0, i}$, $i \in[1, N]$,

$\left[L_{0}\right]=\left[\begin{array}{llll}L_{0,1}, & L_{0,2}, \quad \ldots . L_{0, N-1}, & L_{0, N}\end{array}\right]^{T}$

The part growth produced displacement in $x$ direction is,

$$
\left\{\begin{array}{c}
{[X]=[\xi]\left[L_{0}\right]} \\
\xi(i, j) \in[0,1] \\
\xi(i, i)=1
\end{array}\right.
$$

According to assumptions (4) and (5) in Section 2.2, the part growth produced position error is,

$$
\begin{aligned}
{\left[E_{\text {growth }}\right] } & =[X]-I\left[L_{0}\right] \\
& =\left[\begin{array}{ccccc}
0 & 0 & & 0 \\
e_{g}(1,2) & 0 & 0 & 0 & \\
& & \cdots & 0 & 0 \\
e_{g}(1, N) & & & e_{g}(N-1, N) & 0
\end{array}\right]
\end{aligned}
$$

where $e_{g}(i, j)$ is the machining of the pocket $j$ produced error at the pocket $i$.

The part growth produced position error at the pocket $i$ is,

$$
\Delta_{i}=\sum_{j=1}^{N} e_{g}(i, j)
$$

Fig. 2 Machining distortion produced by pockets from $i+1$ to $N-i-1$

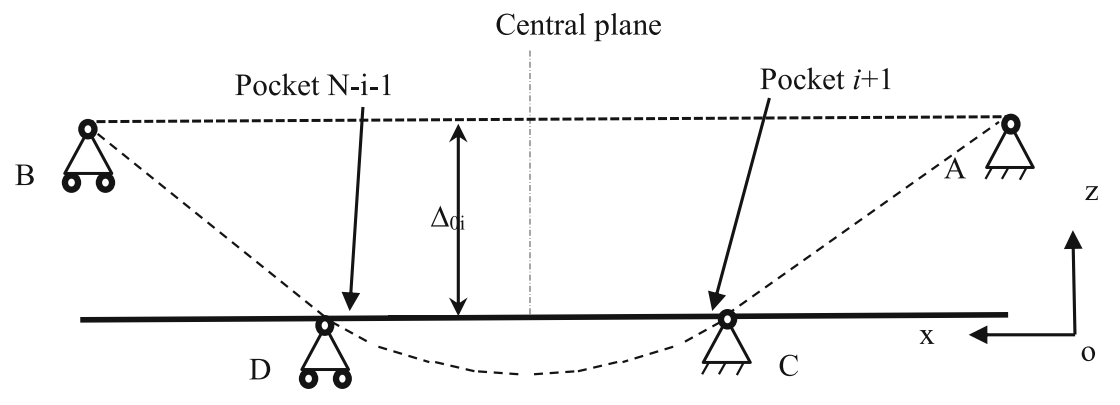


Fig. 3 Simply supported beam AB with $N$ pockets, point A fixed, and machining of pocket $i$ produced part growth, $L_{0 i}$

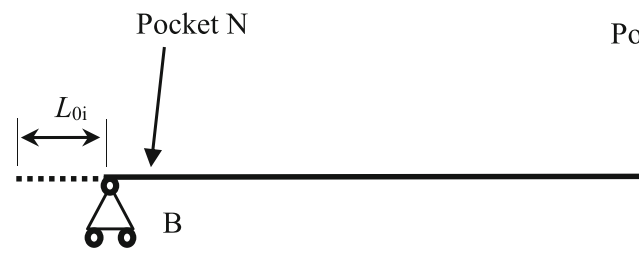

Pocket 1

Pocket $i$

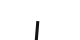

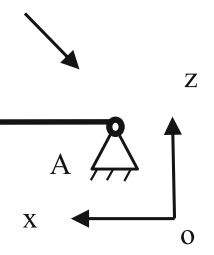

The optimal first pocket to be machined satisfies,

$\operatorname{Min}(\Delta(i), i \in[1, N]), i=1$,

which is the first pocket from the fixed point.

\subsection{The optimal cut $i$ and $i+1$}

The above section proves the optimal cut 1 with regard to the minimum part growth produced position error is the machining of pocket 1 ( $k=1$ is correct). According to mathematic induction, assume that $k=i$ is correct, in this section, $k=i+1$ is going to be proved to be correct as well.

Suppose the optimal cut $i$ with regard to the minimum part growth produced position errors is the machining of the pocket $i$. Then the optimal cut $i+1$ is within the pockets from $i+1$ to $N$. According to assumption (5), the pockets 1 to $i$ can be removed from the error matrix, $E_{\text {growth }}$, in the search of the optimal cut $i+1$. The machining of pockets $i+1$ to $N$ is equivalent with a beam simply supported at $\mathrm{B}$ and $\mathrm{C}$, where support $\mathrm{C}$ is fixed and machining of pocket $j$ produced part growth $L_{0, j}$, as shown in Fig. 4.

Iterate the process for the optimal cut 1 , according to assumptions (4) and (5), and the part growth produced error is,

$$
\begin{aligned}
{\left[E_{\text {growth }}\right] } & =[X]-I\left[L_{0}\right] \\
& =\left[\begin{array}{ccccc}
0 & 0 & & \\
e_{g}(j, j+1) & 0 & 0 & 0 & \\
& & \ldots & 0 & 0 \\
e_{g}(j, N) & & & e_{g}(N-1, N) & 0
\end{array}\right]
\end{aligned}
$$

The part growth produced position error at the pocket $j$ is,

$\Delta_{j}=\sum_{k=i+1}^{N} e_{g}(j, k)$

Fig. 4 Equivalent simply supported beam $\mathrm{BC}$ with pockets $i+1$ to $N$ and fixed at $\mathrm{C}, L_{0, j}$ is pocket $j$ produced part growth
The optimal first pocket to be machined satisfies,

$\operatorname{Min}(\Delta(j), j \in[i+1, N]), j=i+1$,

which is the first pocket from the fixed point.

Iterating the process until pocket $N$, the optimal pocket machining sequence with the minimum part growth produced feature/wall position errors is $1,2 \ldots$, $N$ and the sequence is unique, where the pocket 1 is closest to the fixed end. With the optimal machining sequence, the part growth produced position error, $\Delta_{i}$, is 0 .

\section{Case study and experiment}

The target geometry is a typical pocketed beam in aerospace industry made of aluminum 7075 with dimensions of $744 \mathrm{~mm}$ in length, $172 \mathrm{~mm}$ in width, and $100 \mathrm{~mm}$ in thickness, as shown in Fig. 5. There are 9 pockets in total along the board with side wall thickness of $6.35 \mathrm{~mm}$ and bottom thickness of $12 \mathrm{~mm}$.

Raw billet with work-holding features is shown in Fig. 6. A reaming hole (2) for positioning in $x$ and $y$ on the right, a slot for positioning in $y$ on the left, and three points with bolts for positioning in $z$ hold the part in place.

Part and fixture setup is shown in Fig. 7 and a damping board was applied on the bottom to suppress unwanted vibration.

The dimensions of the part and pockets are shown in Fig. 8 as well as pocket ID for analysis and discussion.

The distortion produced machining errors are so sensitive to the machining sequence that the optimal sequence with the minimized machining errors is required.

FEA can predict the machining distortion with a given machining sequence [5-7]. If there are $N$ pockets on the beam, the amount, $M$, of available machining sequences is a

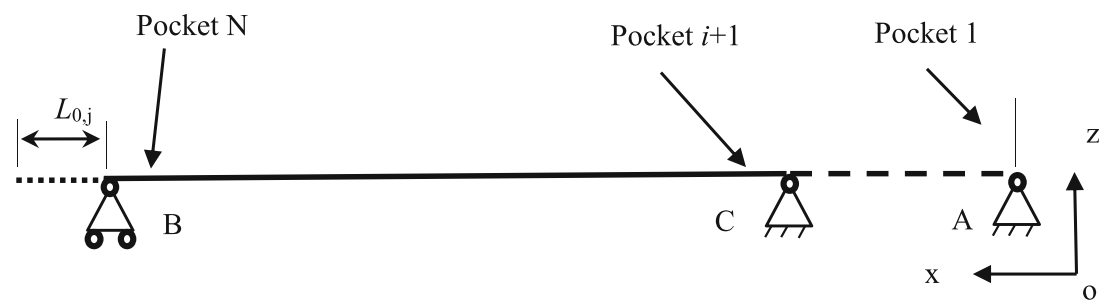


Fig. 5 Target geometry, $744 \mathrm{~mm}$ in length, $172 \mathrm{~mm}$ in width, and 100 in thickness

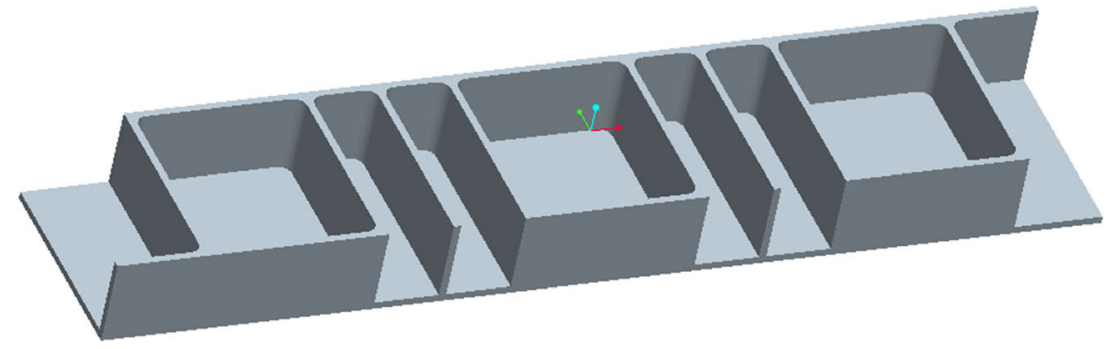

permutation of $N$ elements and when $N=9$, in this case, the amount of available machining sequences is nearly half million,

$M=P(n, n)=N !=9 !=362880$

It is not feasible to optimize the machining sequence by enumeration method on base of FEA due to the huge amount of available sequences.

For the above target geometry, as shown in Fig. 5, the part can be idealized as a beam with 9 pockets, $N=9$, so there are $2^{\text {Int(9/2) }}$ equivalent optimal machining sequences for minimizing the floor height error, according to Eqs. (12) and (13), and the optimal machining sequence for minimizing the part growth produced position error is unique, which is $1,2 \ldots, 9$, according to Eqs. (18) and (21).

In production, the machining can be arranged in two stages most of the time if the part flip over is not required, which are roughing stage and finishing stage. The roughing stage is to make the distortion happen and release the residual stress and the finishing stage, used to have a low dimension in stock, will remove the distortion produced geometrical errors to get a good geometry.

The different machining strategies are required for the different goals of roughing and finishing. The optimal machining sequence for minimizing the floor height error fits the roughing well and the optimal machining sequence for minimizing the part growth produced position errors fits the finishing well due to the low dimension in stock and low bending distortion will be produced.
The following tests were planned in experiment:

(1) Roughing kept $1 \mathrm{~mm}$ dimension in stock for finishing work. The pocket machining order was 9, 1, 8, 2, 7, 3, 6, 4,5 , which is one of the optimal machining sequence with minimum floor height error according to Eqs. (12) and (13).

(2) Finishing cuts the pocket to the final dimension. The pocket machining order was from 1 to 9, which is the optimal machining sequence with minimum wall position errors according to Eqs. (18) and (21).

(3) Top skimming was conducted by removing $0.75 \mathrm{~mm}$ after the pocket finishing cut.

(4) Re-clamping by releasing clamping bolts and reclamping again was carried out to test the fixture performance, including clamping distortion and location repeatability.

Inspection (on-machine inspection or probing) recorded distortion produced errors at critical points. Inspection points are shown in Fig. 9.

Part length inspection was arranged at points P101 and P102. The difference of the two points in $x$ was the length of the part.

Bending distortion was inspected from P401 to P416 on the top surface at the rib intersection points, which will show machining distortion on the top in $z$ until top skimming.
Fig. 6 Raw billet with workholding features on (1) 3 holes for bolts of M12, (2) reaming hole for positioning, and (3) positioning slot

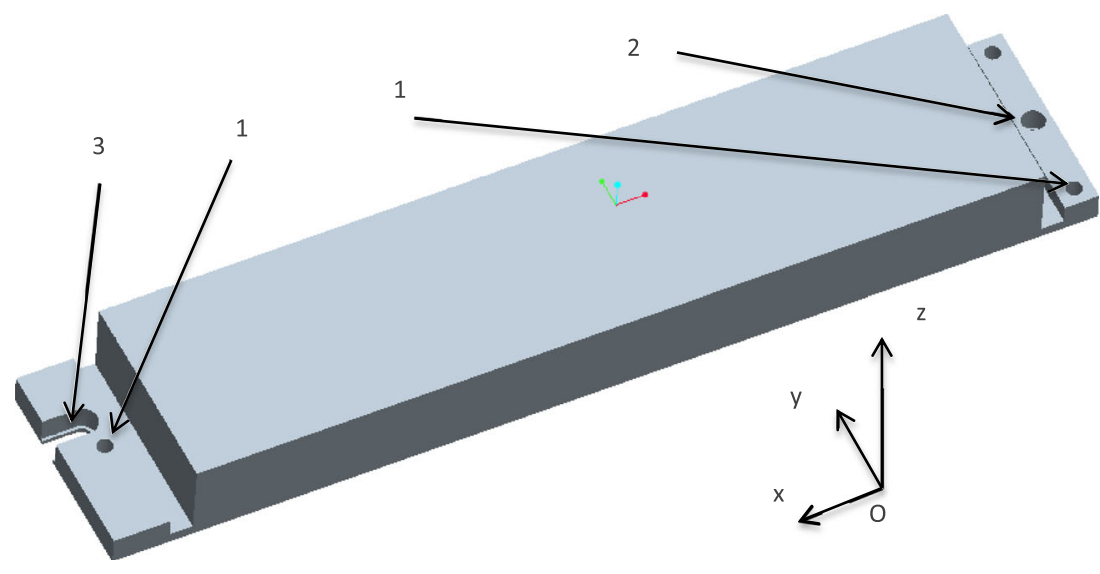


Fig. 7 Part-fixture setup with damping board on bottom

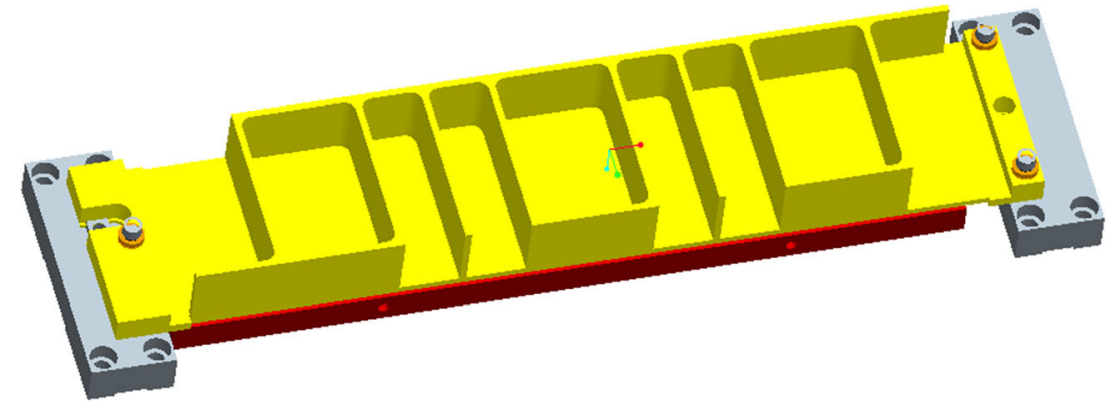

Pocket floor attitudes were inspected from P301 to P309 which are pocket centers for roughing, finishing, top skimming, and re-clamping.

Part growth produced rib position errors were inspected from P201 to P216. The average of P201 and P202 in $x$ is the rib position of rib 1 ; with this process, we can have positions of the 8 ribs. These points keep the same height, $15 \mathrm{~mm}$, from the pocket bottom to minimize the effects of wall verticality and wall root.

Machining distortion produced part growth is shown in Fig. 10. After roughing, the part growth is $0.719 \mathrm{~mm}$ and finishing produced part growth of $-0.086 \mathrm{~mm}$. Top skimming will not introduce a considerable part growth. Re-clamping produced part growth is only $0.018 \mathrm{~mm}$.

Bending distortion was inspected on the top surface which was not cut in either roughing or finishing and revealed the bending distortion in both roughing and finishing, even reclamping.

Bending distortion is shown in Fig. 11. Roughing distortion ranged from 0.054 to $-0.52 \mathrm{~mm}$. The maximum roughing produced distortion was $-0.520 \mathrm{~mm}$ at $\mathrm{P} 410$ and the maximum finishing produced distortion was $-0.172 \mathrm{~mm}$ at the same point. The combined distortion produced by roughing and finishing was $-0.693 \mathrm{~mm}$. Re-clamping produced maximum distortion was $-0.028 \mathrm{~mm}$ at $\mathrm{P} 413$ and P415 at the far end with the single bolt.

Distortion produced machining errors were inspected at the pocket centers, as shown in Fig. 12. Before machining, the geometry errors on the pocket centers ranged from -0.124 to $0.051 \mathrm{~mm}$. After roughing, the machining errors on the pocket centers were between -0.305 and $0.172 \mathrm{~mm}$. Comparison of the machining distortions on the top faces produced during the roughing operations showed that the machining error was $83 \%$ of the roughing distortion and the distortion was shared into pocket 2 and pocket 8 rather than the middle pocket 5 . After finishing, the machining error at the pocket center varied from -0.037 to 0.027 , which is only $9.3 \%$ of the combined distortion $(0.69 \mathrm{~mm})$. Top skimming produced error varied from -0.038 to $0.026 \mathrm{~mm}$, which is also $9.3 \%$ of the combined distortion. Re-clamping produced distortion was within $(-0.044 \mathrm{~mm}, 0.030 \mathrm{~mm})$, on the same level of the error of the finishing.

Part growth produced rib position error was inspected on both sides of each rib. To minimize the root and wall verticality introduced error, the inspection points are selected $15 \mathrm{~mm}$ above/away from the pocket bottom. The average of $x$ values on both sides of a rib is the position of the rib, which was compared to designed values to get the position errors.

Rib position errors are shown in Fig. 13 using rib 1 as 0 point, where the ribs are numbered from the dead point to the far end by $1,2 \ldots, 8$. Roughing produced rib position error reached the maximum at rib 8 , which is $0.575 \mathrm{~mm}$. Finishing produced rib position error is up to $-0.018 \mathrm{~mm}$, nearly the machine tool limit (estimated \pm 0.005 ). After top skimming, the errors keep original values. Re-clamping only introduced position errors less than $0.005 \mathrm{~mm}$.

In production, the process design depends on tolerances of the floor height errors and feature position errors. If the feature position error takes priority, the machining strategy should follow the same sequence as used in the machining trial, which is the machining sequence for minimum floor height error used in roughing and the sequence for minimum length
Fig. 8 Dimensions and pocket ID, (1) to (9)

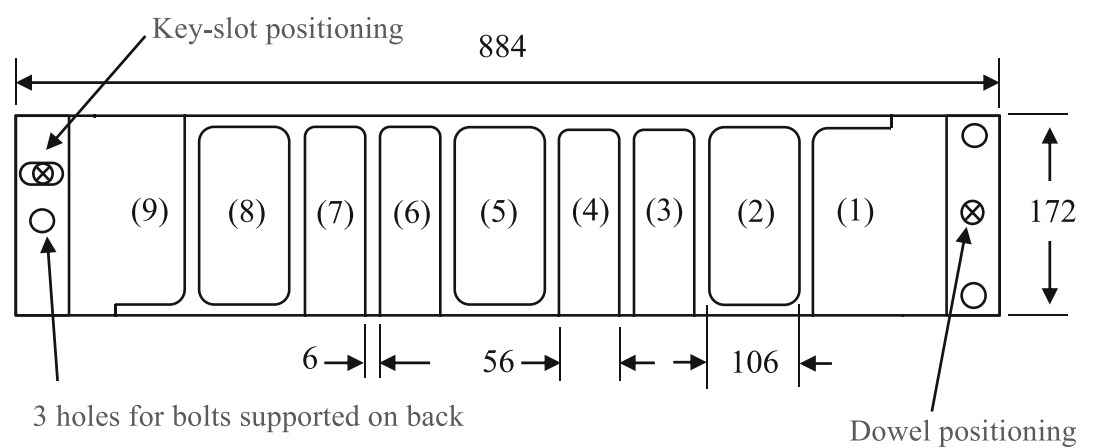


Fig. 9 Inspection points
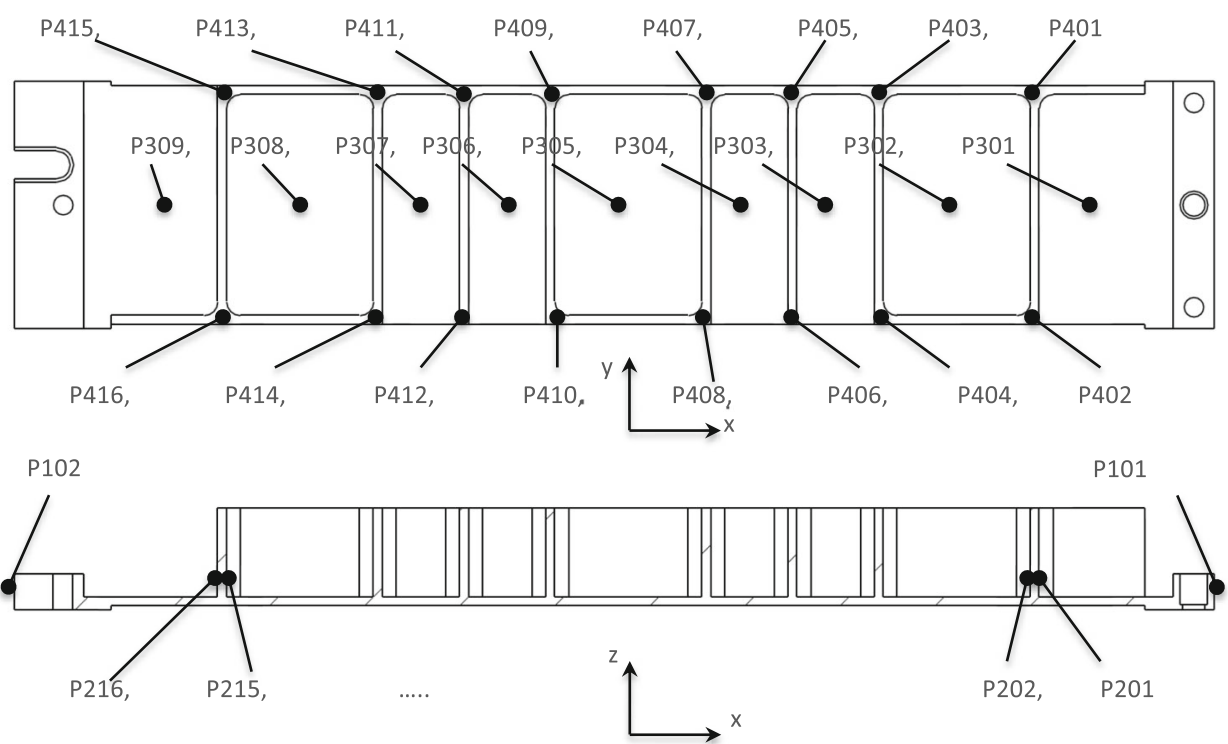

error used in finishing. On the contrary, if the floor height error takes the priority, the strategy should be the machining sequence for minimum floor height error used for both roughing and finishing. It is expected the rib position error is bigger than the first machining strategy, whereas the floor height error will be further reduced compared to the first machining strategy.

\section{Conclusion}

From the above analysis and experimentation, the following conclusions can be drawn as well as recommendations:

(1) A superposition principle-based error modelling method was proposed to formulate the pocket sequence machining distortion and distortion produced machining errors on the simply supported beam.
(2) By this method, the pocket machining error of the structure part was formulated and the machining sequence was optimized with two typical objectives: the minimum bending machining error and the minimum part growth produced feature position errors.

(3) For a simply supported long structural part with $N$ pockets to be machined, the optimal machining sequence with the minimum floor height error is the pocket 1 and $N$ for the cut 1 , the pocket 2 and $N-$ 1 for the cut 2 , and the pocket 3 or $N-2$ for the cut 3 , until $\operatorname{int}(N / 2)$. The optimal sequence is not unique and there are $2^{\operatorname{int}(N / 2)}$ equivalent sequences, in the study case, $N=9$, and the equivalent optimal sequence number is $2^{4}=16$.

(4) For a simply supported long structural part with $N$ pockets to be machined, the optimal machining sequence with the minimum feature/wall position error is from the pocket 1 to $N$, where the pocket 1 is the closest to the
Fig. 10 Machining produced part growth in roughing, finishing, top skimming, and re-clamping

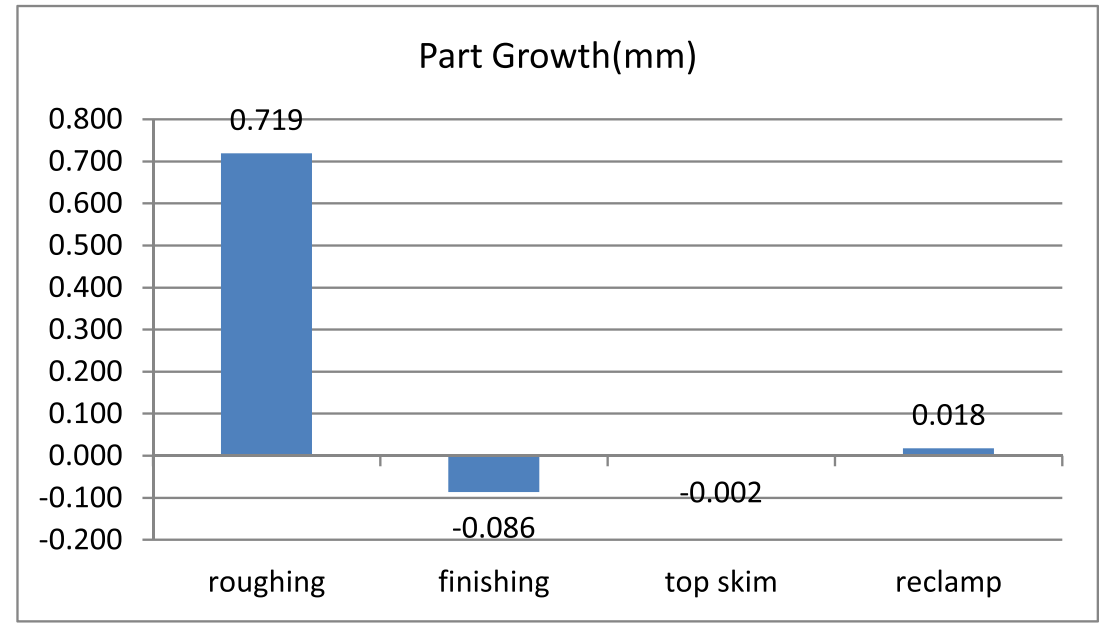


Fig. 11 Bending distortions in roughing, finishing, re-clamping, and roughing \& finishing $(R \& F)$

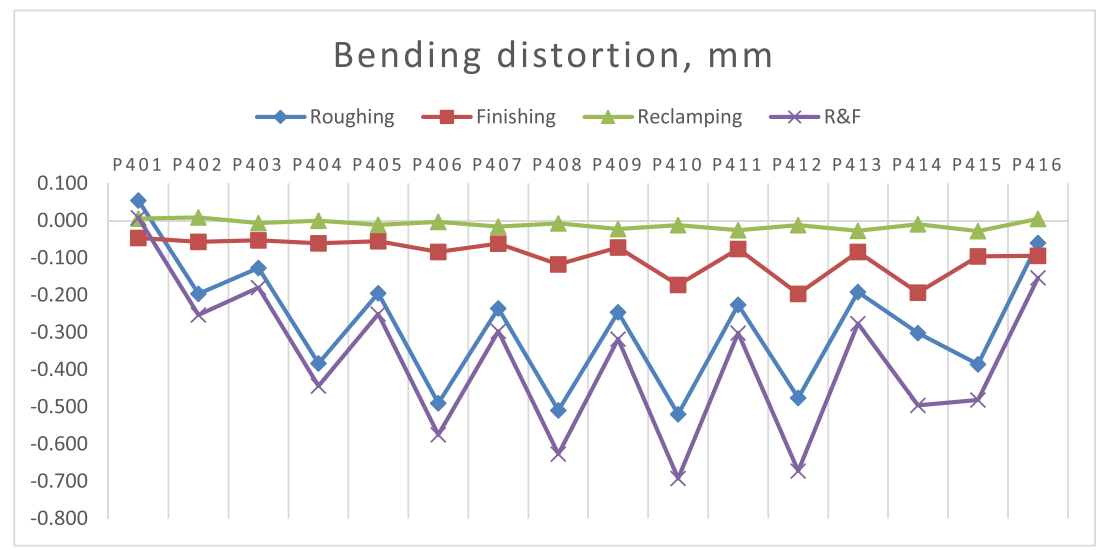

fixed point. The optimal sequence is unique. In the current research, $N=9$, and the optimal sequence is from 1 to 9.

(5) The optimal machining strategies with the minimum floor height error and minimum feature/wall position error only apply for the given work-holding layout and may not be applicable in an over-constrained fixture.

(6) The machining test showed the maximum machining distortion happens in the middle of the structure part. With the optimal machining sequence with the minimum floor height error, the distortion was shared between the pockets on both sides and the pocket in the middle had a theoretically minimized (0) floor height error and the maximum floor height error can be reduced by $17 \%$.

(7) The machining test also showed that if the optimal machining sequence with the minimum feature position errors was not used, the feature/wall position error was on the same level of the part growth. In this project, the part growth was $0.719 \mathrm{~mm}$ and rib position error produced was $0.575 \mathrm{~mm}$. On the contrary, when the optimal machining sequence with the minimum position error was used, the maximum rib position error is only $0.018 \mathrm{~mm}$, which was close to the machine tool accuracy limit (estimated $\pm 0.005 \mathrm{~mm}$ ).

In the next stage, the research will be focused on the following: (1) the optimal pocket machining sequence for the pocketed cantilever; (2) the optimal pocket machining sequence for a non-end supported pocketed beam; (3) the quantitative error difference between specific machining sequences; (4) the relationship between distortion and distortion produced error; (5) the error distribution along the beam with a specific machining sequence; (6) determine the optimal pocket machining sequence of a pocketed plate/board and even the tool path of pocket machining on the base of the above results. A non-end supported beam can be idealized as an end supported beam plus one or two cantilevers and then the non-end supported beam can be converted into a cantilever and end supported beam combination. The continuous machining can be idealized as infinite small pockets with zero wall thickness between and the continuous machining, such as surfacing, can also be treated as a pocketed beam or board with the same/
Fig. 12 Floor height errors in roughing, finishing, top skimming, and re-clamping

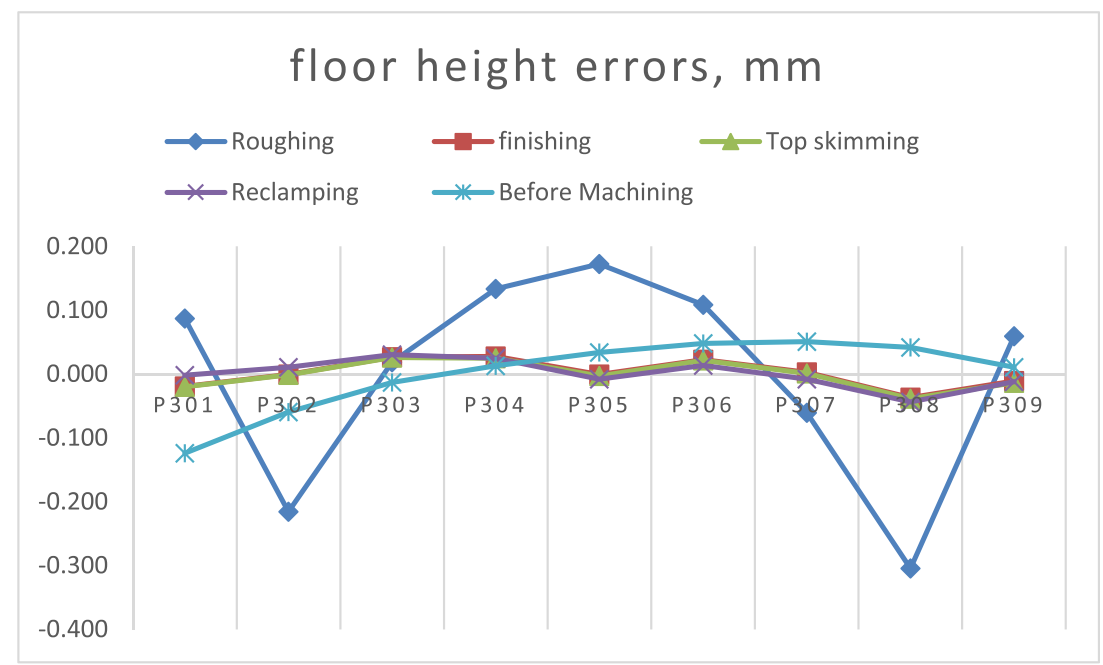


Fig. 13 Rib position errors

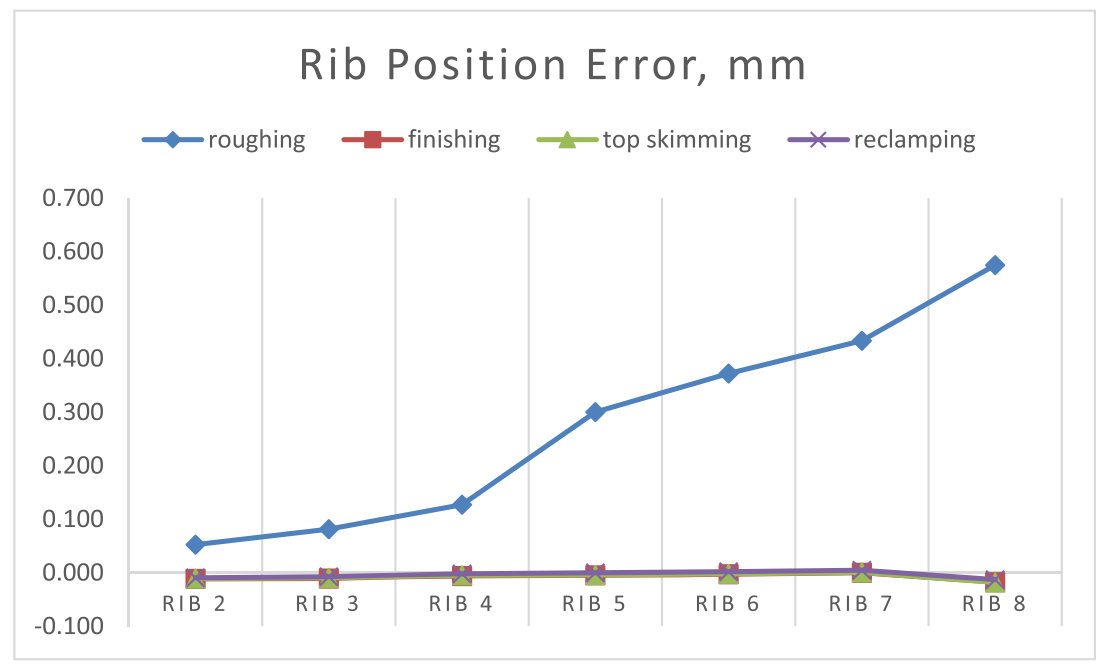

similar optimal sequences. So the pocketed beam machining is a typical and representative case and the results and conclusions can be extended to two-dimensional board/plate and even continuous cutting, such as surfacing.

Funding The research is financially supported by Catapult, project code: 152590 .

Open Access This article is licensed under a Creative Commons Attribution 4.0 International License, which permits use, sharing, adaptation, distribution and reproduction in any medium or format, as long as you give appropriate credit to the original author(s) and the source, provide a link to the Creative Commons licence, and indicate if changes were made. The images or other third party material in this article are included in the article's Creative Commons licence, unless indicated otherwise in a credit line to the material. If material is not included in the article's Creative Commons licence and your intended use is not permitted by statutory regulation or exceeds the permitted use, you will need to obtain permission directly from the copyright holder. To view a copy of this licence, visit http://creativecommons.org/licenses/by/4.0/.

\section{References}

1. Hornbach D, Prevey P (1998) Development of machining procedures to minimize distortion during manufacture, Heat Treating 1998. In: Proceedings of the $17^{\text {th }}$ Heat Treating Society Conference and Exposition, Lambda Technologies. ASM, pp 1318

2. Ratchev S, Lui S, Huang W, Becker AA (2004) Milling error prediction and compensation in machining of low rigidity parts. Int $\mathrm{J}$ Mach Tool Manu 44:1629-1641
3. Wang ZJ, Chen WY, Zhang YD, Chen ZT, Liu Q (2005) Study on the machining distortion of thin walled part caused by redistribution of residaul stress. Chin J Aeronaut 18(2):175-180

4. Guo H, Zuo DW, Wu HB, Xu F, Tong GQ (2009) Prediction on milling distortion for aero multi frame parts. Mater Sci Eng A 499: 230-233

5. Bi YB, Cheng QL, Dong HY, Ke YL (2009) Machining distortion prediction of aerospace monolithic components. J Zheijang Univ Sci A 10(5):661-668

6. Mei ZG, Wang YQ, Amir S (2011) Distortion analysis of arc shaped workpiece in NC machining. In: Proceedings of the World Congress on Engineering. III. WCE2011

7. Cerutti X, Mocellin K (2016) Influence of the machining sequence on the residual stress redistribution and machining quality: analysis and improvement using numerical simulations. Int J Adv Manuf Technol 83:489-503

8. Mocellin K, Cerutti X (2016) Numerical prediction of distortions during machining of large aluminium aeronautical parts. Mat-wiss u Werkstofftech 47(8):699-710

9. Jiang XH, Wang YF, Ding ZS, Li HL (2017) An approach to predict the distortion of thin-walled parts affected by residual stress during the milling process. Int J Adv ManufTechnol 93:4203-4216

10. Casuso M, Polvorosa R, Veiga F (2020) Residual stress and distortion modeling on aeronautical aluminum alloy parts for machining sequence optimization. Int J Adv Manuf Technol 110:1219-1232

11. Li BH, Deng HB, Hui D (2020) A semi-analytical model for predicting the machining deformation of thin walled parts considering machining induced and blank initial residual stress. Int J Adv Manuf Technol 110:139-161

12. Ye HC, Qin GH, Wang HM (2020) A machining position optimization approach to workpiece deformation control for aeronautical monolithic components. Int J Adv Manuf Technol 109:299-313

Publisher's note Springer Nature remains neutral with regard to jurisdictional claims in published maps and institutional affiliations. 